\title{
Instrument concept of the imaging Fourier transform spectrometer GLORIA
}

\author{
F. Friedl-Vallon ${ }^{1}$, T. Gulde ${ }^{1}$, F. Hase ${ }^{1}$, A. Kleinert ${ }^{1}$, T. Kulessa ${ }^{4}$, G. Maucher ${ }^{1}$, T. Neubert ${ }^{3}$, F. Olschewski ${ }^{6}$, C. Piesch ${ }^{1}$, \\ P. Preusse $^{2}$, H. Rongen ${ }^{3}$, C. Sartorius ${ }^{1}$, H. Schneider ${ }^{4}$, A. Schönfeld ${ }^{2}$, V. Tan ${ }^{2}$, N. Bayer ${ }^{4}$, J. Blank ${ }^{2}$, R. Dapp $^{5}$, \\ A. Ebersoldt ${ }^{5}$, H. Fischer ${ }^{1}$, F. Graf ${ }^{1}$, T. Guggenmoser ${ }^{2, *}$, M. Höpfner ${ }^{1}$, M. Kaufmann ${ }^{2}$, E. Kretschmer ${ }^{1}$, T. Latzko ${ }^{1}$, \\ H. Nordmeyer ${ }^{1}$, H. Oelhaf ${ }^{1}$, J. Orphal ${ }^{1}$, M. Riese ${ }^{2}$, G. Schardt ${ }^{3}$, J. Schillings ${ }^{4}$, M. K. Sha ${ }^{1}$, O. Suminska-Ebersoldt ${ }^{1}$, \\ and J. Ungermann ${ }^{2}$ \\ ${ }^{1}$ Institut für Meteorologie und Klimaforschung, Karlsruher Institut für Technologie, Karlsruhe, Germany \\ ${ }^{2}$ Institut für Energie und Klimaforschung - Stratosphäre, Forschungszentrum Jülich, Jülich, Germany \\ ${ }^{3}$ Zentralinstitut für Engineering, Elektronik und Analytik - Systeme der Elektronik, Forschungszentrum Jülich, \\ Jülich, Germany \\ ${ }^{4}$ Zentralinstitut für Engineering, Elektronik und Analytik - Engineering und Technologie, Forschungszentrum Jülich, \\ Jülich, Germany \\ ${ }^{5}$ Institut für Prozessdatenverarbeitung und Elektronik, Karlsruher Institut für Technologie, Karlsruhe, Germany \\ ${ }^{6}$ Fachbereich C - Atmosphärenphysik, Bergische Universität Wuppertal, Wuppertal, Germany \\ *now at: European Space Agency, Noordwijk, The Netherlands \\ Correspondence to: F. Friedl-Vallon (felix.friedl-vallon@kit.edu)
}

Received: 17 February 2014 - Published in Atmos. Meas. Tech. Discuss.: 7 March 2014

Revised: 11 August 2014 - Accepted: 3 September 2014 - Published: 20 October 2014

\begin{abstract}
The Gimballed Limb Observer for Radiance Imaging of the Atmosphere (GLORIA) is an imaging limb emission sounder operating in the thermal infrared region. It is designed to provide measurements of the upper troposphere/lower stratosphere with high spatial and high spectral resolution. The instrument consists of an imaging Fourier transform spectrometer integrated into a gimbal. The assembly can be mounted in the belly pod of the German High Altitude and Long Range research aircraft (HALO) and in instrument bays of the Russian M55 Geophysica. Measurements are made in two distinct modes: the chemistry mode emphasises chemical analysis with high spectral resolution, and the dynamics mode focuses on dynamical processes of the atmosphere with very high spatial resolution. In addition, the instrument allows tomographic analyses of air volumes. The first measurement campaigns have shown compliance with key performance and operational requirements.
\end{abstract}

\section{Introduction}

The upper-troposphere/lower-stratosphere (UTLS) region plays a crucial role in the climate system. Surface temperature is sensitive to changes in the dynamic structure and composition of this region (Solomon et al., 2010; Riese et al., 2012). The goal of the Gimballed Limb Observer for Radiance Imaging of the Atmosphere (GLORIA) project is to achieve substantially improved spatial resolution and spatial coverage in observing the UTLS by airborne remote sensing. Scientific applications for the improved spatial performance range from addressing questions of atmospheric dynamics to understanding chemical fine structures (Riese et al., 2014). GLORIA also serves to demonstrate the potential of this technique for observations from space.

Limb emission sounding in the thermal infrared region is a mature technique that has been used on airborne and spaceborne platforms for earth observation for more than 3 decades. Radiometers such as LIMS (Gille and Russell, 1984) and HIRDLS (Gille and Barnett, 1996), Fourier transform spectrometers (FTS) such as SIRIS, MIPAS and TES 
(Kunde et al., 1987; Oelhaf et al., 1994; Beer et al., 2001; Fischer et al., 2008), and dispersive spectrometers such as CRISTA (Offermann et al., 1999) have been employed. The majority of these instruments scan the atmospheric limb in a vertical direction with the aid of a mirror system. TES is designed to observe part of the atmospheric limb simultaneously with a linear detector array with 16 elements. Larger linear and two-dimensional infrared detector arrays have become available in the last 2 decades and were used in a nadir sounding operational grating spectrometer (Aumann et al., 2003) and in a prototype imaging FTS nadir sounder for atmospheric research (Elwell et al., 2006). Development of an operational imaging FTS nadir sounder has commenced (Rodriguez et al., 2009). In parallel, commercial imaging FTSs for military and security applications (Vallieres et al., 2005; Sabbah et al., 2012) based on large focal plane arrays have been realised in recent years. However, none of these instruments has the spectral coverage, sensitivity and spectral resolution that are needed for an imaging limb sounder for atmospheric research. Accordingly, a development of an instrument optimised for the requirements of limb sounding from an airborne platform had to be undertaken.

Section 2 discusses the requirements, and Sect. 3 outlines the main design trade-offs. A condensed description of the instrument design follows. Section 4 shows essential characterisation results and discusses to what extent the most important requirements can be achieved.

\section{Instrument requirements}

A brief summary of the science at the beginning of the section will outline the background for the discussion of the instrument requirements. A detailed discussion of the scientific aims and associated references can be found in Riese et al. (2014).

The scientific focus of GLORIA is on the region of the UTLS, due to its immense importance for the climate system. Composition and dynamic structure of this region are governed by the complex interaction of various physical and chemical processes, operating at a wide range of temporal and spatial scales. Currently, there is a gap between global satellite observations and airborne in situ measurements in terms of spatial resolution and coverage. Greenhouse gases such as water vapour and ozone exhibit steep vertical and horizontal concentration gradients in the UTLS, which give rise to small-scale variability. A prominent process is stratosphere-troposphere exchange (STE), including convective uplift of moist air in the tropics as well as quasihorizontal (isentropic) exchange between the upper tropical troposphere and extra-tropical lowermost stratosphere. These transport processes are accompanied by pronounced trace gas structures such as tropopause folds or filaments. Filamentary trace gas structures typically exhibit a horizontal diameter of the order of $100 \mathrm{~km}$ and a vertical extension of a few hundred metres (see, e.g., Bacmeister et al., 1999; Pan et al., 2009; Weigel et al., 2012; Barré et al., 2012; Ungermann et al., 2013).

In addition to STE, long-range transport of pollutants significantly influences UTLS composition, in particular the ozone budget in the upper troposphere. Long-range transport of pollutants involves a large number of scientifically interesting chemical compounds and is also associated with pronounced small-scale structures. Finally, the investigation of important dynamical processes such as gravity-wave excitation and propagation or the formation of the tropopause inversion layer (TIL) require three-dimensional observations of structures in temperature, radiatively active trace gases and cloud parameters with a horizontal resolution of a few tens of kilometres and a vertical resolution of a few hundred metres.

To address the scientific questions outlined above, GLORIA was designed to employ two distinct measurement modes. The first one, called the chemistry mode (CM), focuses on high spectral resolution and thus maximises the number of retrieved trace species with sufficient spatial sampling for the aforementioned structures. The second one, called the dynamics mode (DM), has lower spectral resolution but provides further increased horizontal resolution and is able to undertake three-dimensional sounding of temperature and a limited number of species. The geometric and spectral requirements of the two modes are summarised in Tables 1 and 2. In order to improve the long-term benefit of GLORIA, instrument requirements include the ability to choose other compromises between spectral and spatial resolution and the ability to perform nadir viewing.

The first group of requirements (Table 1) deals with observation geometry, observation coverage and spatial and temporal sampling of the measurements. The nature of the requirements dictated the principal design decisions for the instrument. The quest for high vertical resolution directly leads to the concept of a limb sounder. The demanding requirements concerning simultaneous vertical coverage and temporal sampling compel us to use an imaging optical system with very high throughput. The goal of performing tomographic measurements could only be achieved with angular agility of the instrument in yaw direction. The use of a research aircraft as a carrier, with its inevitable pitch, roll and yaw movements during flight, made a three-axis stabilisation of the field of view (FOV) during measurement recording indispensable.

The specific values for the above-mentioned requirements (Table 1) are motivated by the following considerations: scientific interest in the free troposphere requires us to set the value for the lower boundary of the vertical coverage to approximately $4 \mathrm{~km}$ altitude. Viewing by up to $0.8^{\circ}$ above the horizon provides some information on trace gas column amounts above the aircraft (Woiwode et al., 2012).

Infrared limb sounding is capable of providing vertical resolutions in the 300 to $400 \mathrm{~m}$ range (Ungermann, 2011; Ungermann et al., 2011). Consequently, the vertical sampling should be in the range of a few hundred metres at the tangent 
Table 1. Instrument specifications - geometry.

Translation from angular values to distance is made for an observer altitude of $15 \mathrm{~km}$ and a tangent altitude of $10 \mathrm{~km}$.

\begin{tabular}{ll}
\hline Requirement & Value \\
\hline Vertical spatial coverage & \\
Lower boundary & $-3.3^{\circ}$ below local horizon, typ. equal to $4 \mathrm{~km}$ altitude \\
Upper boundary & $0.8^{\circ}$ above local horizon \\
Vertical sampling & Required: $<3$ arcmin \\
& Achieved: 1.9 arcmin, equal to $140 \mathrm{~m}$ \\
Horizontal spatial coverage & Typically $1.5^{\circ}$, equal to $6.7 \mathrm{~km}$ \\
Yaw pointing range & 45 to $135^{\circ}$ \\
Temporal sampling & Required: $<3 \mathrm{~s} /<30 \mathrm{~s}$ for $\mathrm{DM} / \mathrm{CM}$ \\
& Current parametrisation: \\
& $1.2 \mathrm{~s} / 12 \mathrm{~s}$ interferogram length for DM/CM \\
& $2 \mathrm{~s} / 12.8 \mathrm{~s}$ temporal sampling for DM/CM \\
Pointing stability (vertical) & 0.7 arcmin, equal to $50 \mathrm{~m}(1 \sigma)$ \\
\hline
\end{tabular}

point to be compliant with this resolution. The retrieval study of Ungermann et al. (2011) further indicates that the horizontal FOV size should not be much larger than $10 \mathrm{~km}$ at a tangent altitude of $10 \mathrm{~km}$ to be compatible with the tomographic retrieval approach and that the yaw angle should be adjustable to between 45 and $135^{\circ}$. In addition, finer subsampling in horizontal direction should be possible for cloud identification and analysis.

The achieved values of 1.9 arcmin vertical and horizontal pixel size reflect the properties of the detector array and the chosen optical system. The typical horizontal sample size of $1.5^{\circ}$ mentioned in Table 1 represents the integration over a row of 48 pixels. These values correspond to a sample size of $140 \mathrm{~m}$ vertically and about $6.7 \mathrm{~km}$ horizontally at a tangent altitude of $10 \mathrm{~km}$ seen from an observer altitude of $15 \mathrm{~km}$.

The second group of requirements (Table 2) deals with the spectrometer itself: the goal of covering, at least, emission bands of carbon dioxide, ozone, water vapour, nitric acid, some chlorofluorocarbons, nitrous oxide, chlorine nitrate and methane in the thermal infrared region leads to a broad spectral coverage requirement of the instrument. Chlorine nitrate determines the spectral wave number cut-on to be approximately $780 \mathrm{~cm}^{-1}$; water vapour and methane force to measure the spectral range up to $1400 \mathrm{~cm}^{-1}$. The spectral sampling requirement of $0.0625 \mathrm{~cm}^{-1}$ for the chemistry mode is based on experience with the MIPAS FTS (von Clarmann et al., 2009; Friedl-Vallon et al., 2004); the requirement of $0.625 \mathrm{~cm}^{-1}$ for the dynamics mode is based on experience with the CRISTA dispersive spectrometer (Riese et al., 1997, 1999) and on studies performed for a satellite-borne imaging FTS (ESA, 2012). The sensitivity requirements of target (threshold) $5 \mathrm{nW}\left(\mathrm{cm}^{2} \mathrm{sr} \mathrm{cm}^{-1}\right)^{-1}$ $\left(10 \mathrm{nW}\left(\mathrm{cm}^{2} \mathrm{srcm}^{-1}\right)^{-1}\right)$ for the dynamics mode and $15 \mathrm{nW}\left(\mathrm{cm}^{2} \mathrm{srcm}^{-1}\right)^{-1}\left(30 \mathrm{nW}\left(\mathrm{cm}^{2} \mathrm{sr} \mathrm{cm}^{-1}\right)^{-1}\right)$ for the chemistry mode are derived from the comparable performances of the precursor instruments. Experience with these precursor instruments has also proven that the radiometric and spectral accuracy requirements of a $1 \%$ target $(2 \%$ threshold) and 10 ppm respectively are necessary and sufficient.

A third group of requirements, not mentioned in the tables, is of a technical nature. The instrument needs to operate on aircraft that are able to reach the lower stratosphere. GLORIA is primarily designed for use on the German High Altitude and Long Range research aircraft (HALO), which is based on a commercial Gulfstream G550 business jet (see Fig. 1). However, the use of the instrument on other aircraft, notably on the Russian M55 Geophysica research aircraft, has to be provided for. Accordingly, environmental requirements for temperature inside the instrument compartment as low as $-50^{\circ} \mathrm{C}$ and for ambient pressure as low as $70 \mathrm{hPa}$ have to be taken into account. The instrument will be exposed to vibrations excited by the aircraft turbines and by aerodynamics. Precise quantification of excitation levels is difficult before flight, since the instrument itself, its mounting position and the aerodynamic fairing influence the vibration environment. Finally, the instrument has to be certified for operation on the aircraft. In particular, the certification for the HALO is demanding, since HALO in the long term will be able to operate as a civil aircraft, without flight restrictions imposed by the instrumentation.

\section{Instrument concept}

\subsection{Overview}

The GLORIA spectrometer is a cooled imaging Fourier transform spectrometer (IFTS) with a large cryogenic $\mathrm{HgCdTe}$ detector array for detection of infrared (IR) radiation. The spectrometer is mounted in a gimbal that allows agility in pitch, roll and yaw direction. The instrument is designed to be mounted outside of the aircraft cabin. Calibration sources are two large-area blackbodies and a "deep space" view for radiometric and spectral calibration. 
Table 2. Instrument requirements - spectrometry (given as target/threshold, where applicable). NESR stands for "noise equivalent spectral radiance".

\begin{tabular}{ll}
\hline Requirement & Value \\
\hline Spectral coverage & $780-1400 \mathrm{~cm}^{-1}$ \\
Spectral sampling & $<0.625 \mathrm{~cm}^{-1} /<0.0625 \mathrm{~cm}^{-1}$ for DM/CM \\
Sensitivity (NESR) & $<5 \mathrm{nW}\left(\mathrm{cm}^{2} \mathrm{srcm}^{-1}\right)^{-1}\left(10 \mathrm{nW}\left(\mathrm{cm}^{2} \mathrm{srcm}^{-1}\right)^{-1}\right)$ for DM \\
& $<15 \mathrm{nW}\left(\mathrm{cm}^{2} \mathrm{srcm}^{-1}\right)^{-1}\left(30 \mathrm{nW}\left(\mathrm{cm}^{2} \mathrm{srcm}^{-1}\right)^{-1}\right)$ for CM \\
Radiometric gain accuracy & $1 \% / 2 \%$ \\
Spectral accuracy & $10 \mathrm{ppm}$ \\
\hline
\end{tabular}

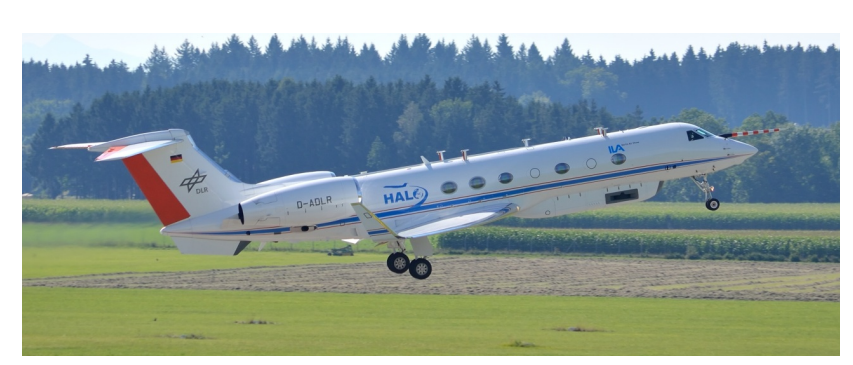

Figure 1. HALO fully equipped during take-off. The image was taken during the preparations for the TACTS campaign. GLORIA is mounted in the belly pod below the aircraft.

A graphical overview of the instrument is given in Fig. 2, and a picture of the instrument mounted in the HALO aircraft is found in Fig. 3. Table 3 provides a summary of key properties.

An IFTS was chosen as the baseline spectrometer concept in order to benefit from the massive total throughput advantage of nearly two orders of magnitude that this kind of instrument offers in comparison to a conventional FTS. This advantage is essential in achieving the required spatial and temporal sampling. Any scanning system, FTS or grating, would need a very large entrance aperture to achieve the same throughput. Such a large opening would be difficult to implement on an aircraft. Further arguments for the imaging FTS are its flexibility in spectral and spatial resolution and the non-availability of infrared detector arrays that support a high spectral resolution dispersive system.

Although state-of-the-art IR detector systems still suffer from significant electronic noise, photon noise in our case substantially contributes to the noise performance. Furthermore, a high photon background limits integration time since the full well capacity of the integration capacitors in the readout integrated circuit is finite. This limitation has a direct impact on the sensitivity. Thus, a reduction of the optics temperature from room temperature to $220 \mathrm{~K}$ leads to a signalto-noise advantage of roughly a factor of 3 for a spectrometer using the infrared detector arrays available to the project (see Sect. 3.2). This fact led us to design an actively cooled spectrometer.
Table 3. Basic instrument properties.

\begin{tabular}{ll}
\hline Property & Value \\
\hline Mass of instrument & $212 \mathrm{~kg}$ \\
Mass of control computer & $28 \mathrm{~kg}$ \\
Overall length & $1610 \mathrm{~mm}$ \\
Overall width & $975 \mathrm{~mm}$ \\
Overall height & $675 \mathrm{~mm}$ \\
Typical total power consumption & $\mathrm{ca} .800 \mathrm{~W}$ \\
Typical raw data rate & $600 \mathrm{Mbit} \mathrm{s}^{-1}$ \\
\hline
\end{tabular}

As mentioned in the requirement section, stabilisation of the FOV in altitude and orientation is essential. This can either be achieved by mounting the spectrometer in a gimbal or by fore-optics with a set of controlled scanning mirrors. Two aspects led to the adoption of a gimbal mount: first, an imaging system has an extended FOV (accordingly, not only elevation and azimuth but also image rotation needs to be stabilised); second, the combination of an image rotation device and azimuth and elevation scanner would have led to a complex optical set-up with many optical elements, a long optical path and, subsequently, large optical elements. It should be noted that a downside of the decision in favour of the gimbal is the very strict limitation on size and mass of the spectrometer.

On HALO, the whole instrument is mounted outside the aircraft in the unpressurised belly pod to avoid a large IR window in the pressurised aircraft cabin. Such a window would have been outside the calibration path, and it would have caused severe flight certification problems. On the M55 Geophysica there is no choice: all instruments have to be mounted in unpressurised compartments. An insulating window is implemented in the spectrometer enclosure to avoid water contamination and reduce aeroacoustic excitation within the spectrometer.

The agility of the gimbal yaw frame allows for in-flight calibration by turning the spectrometer towards the apertures of the two large-area blackbody radiation sources. Thus, the whole optical chain including the spectrometer window is in the calibration path. Due to the high spectral resolution of the spectrometer, a posteriori spectral calibration using atmospheric lines is possible. 
Table 4. Basic spectrometer properties. LFPA stands for "large focal plane array".

\begin{tabular}{ll}
\hline Property & Value \\
\hline Mass of spectrometer & $48 \mathrm{~kg}$ \\
Operating temperature of spectrometer & $200-220 \mathrm{~K}$ \\
Entrance window diameter & $100 \mathrm{~mm}$ \\
Max. optical path difference & $90 \mathrm{~mm}$ double-sided \\
Camera focal length & $72.2 \mathrm{~mm}$ at $218 \mathrm{~K}$ \\
Aperture ratio & $f / 2$ \\
Detector type & $256^{2} \mathrm{HgCdTe}-\mathrm{LFPA}$ by AIM GmbH \\
Pixel pitch & $40 \mu \mathrm{m}$ \\
Operating temperature of detector & $50 \mathrm{~K}$ \\
\hline
\end{tabular}

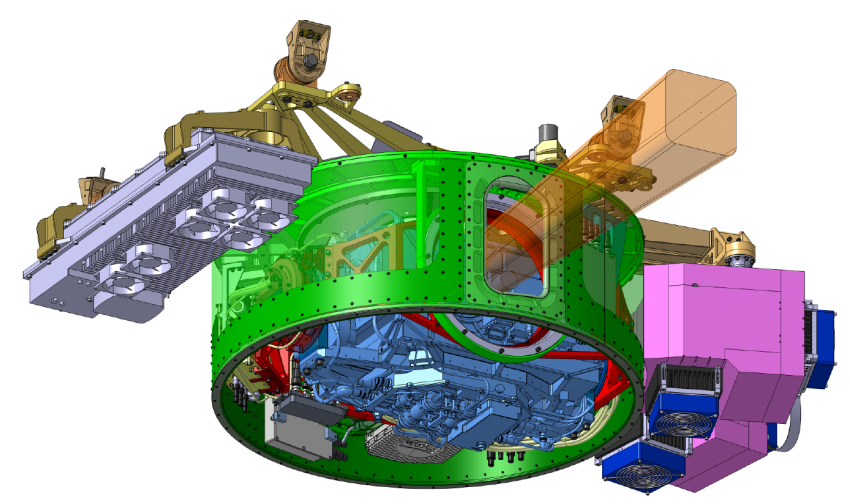

Figure 2. Schematic diagramm of the GLORIA instrument. The different gimbals are colour-coded: blue indicates the pitch frame including spectrometer, red the roll frame, green the yaw frame and gold the mounting frame used to fix the instrument to the aircraft. The transparent orange bar represents the field of view of the instrument. The grey box at the left-hand side is the power electronics; the pink boxes at the right-hand side are the blackbodies for radiometric calibration.

\subsection{Spectrometer}

The GLORIA spectrometer needs to be as compact and rigid as possible. Size and mass are limited within the gimballed frame, and the cooled volume must be kept small. The vibration environment of an aircraft demands a sturdy design with as few optical elements as possible. The optical setup of the interferometer is straightforward and simple (see Fig. 4). The radiation enters through an insulating double germanium window with wedged plates. Amplitude splitting is performed by a dielectric beam splitter on a potassium chloride substrate. Two Zerodur cube corners - one fixed and one linearly moveable - act as retroreflectors. After recombination, the radiation is focused on the focal plane array with an achromatic infrared doublet. The interferometer needs to be enclosed since it is cooled and has hygroscopic components in the infrared optics. The insulating window solution is compact and allows simple testing of the cooled instrument on the ground under ambient conditions.

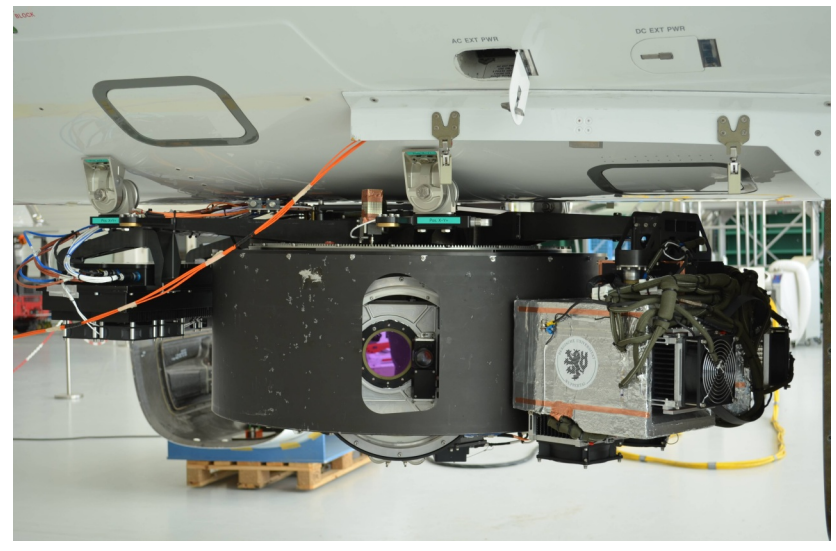

Figure 3. GLORIA mounted on the belly of the HALO aircraft.

Since the task of imaging the limb scene on the detector can be solved without a telescope in front of the interferometer, a telescope was omitted to reduce complexity, volume and mass. Transfer optics between interferometer and detector was avoided to reduce the number of optical components and the spatial envelope. The downside of a larger beam diameter in the interferometer was an acceptable tradeoff given the benefits. A linear interferometer set-up was chosen since it was considered as the most compact and mechanically robust solution. The spectral resolution requirement does not impose a movement of both retroreflectors. The moving cube corner is mounted on a dovetail slide that is driven by a lead screw with a direct-drive motor controlled by an angular high-resolution optical shaft encoder. The approach leads to a system with high-resonance frequencies (Piesch et al., 2014). However, the slide construction requires regular servicing. The interferometer provides a maximum optical path difference (OPD) of up to $9 \mathrm{~cm}$. Two-sided interferograms with $0.8 \mathrm{~cm}$ or with $8 \mathrm{~cm}$ maximum OPD are recorded in dynamics and chemistry mode, respectively.

The quadrature reference system for the optical-path determination is based on a laser diode in the visible spectral domain whose temperature is controlled by a thermoelectric element. The spectral stability of the diode is enhanced by the 


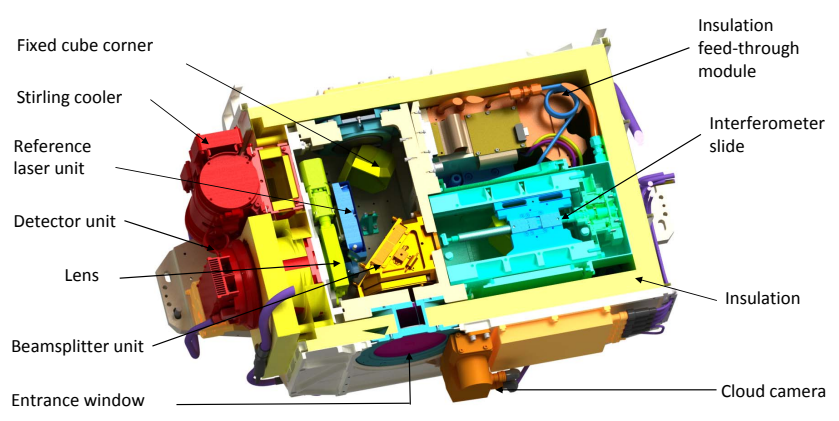

Figure 4. Schematic diagramm of the GLORIA spectrometer including insulation. The instrument is cut in the horizontal plane to show the optical set-up and the slide construction.

use of volume holographic gratings. The design was chosen for its compactness and its ability to operate at low temperatures within the cooled spectrometer.

The infrared radiation is focused on the detector array with an air-spaced aspheric Ge-ZnSe doublet with a focal length of approximately $72.2 \mathrm{~mm}$ at an operating temperature of $218 \mathrm{~K}$. Since the total thermal operating range of the instrument is too large for an athermal design, a motorised thread allows focusing the optics according to operation temperature.

The infrared detector is an $\mathrm{HgCdTe}$ large focal plane array (LFPA) from the German supplier AIM GmbH and has $256 \times 256$ photovoltaic detector elements with a pitch of $40 \mu \mathrm{m}$. It is read out with a $10 \mathrm{MHz}$ clock and eight taps and allows the selection of subframes. Typical frame rates are in the range of several kilohertz, depending on the size of the chosen subframe. Currently, a subframe with $128 \times 48$ elements is used resulting in a frame rate of $6.3 \mathrm{kHz}$. Frame integration time is adjustable and is varied between 30 and $120 \mu \mathrm{s}$, depending on the scene brightness. The read-out circuit allows integration in parallel to the read-out process. The long-wave cut-off of the $\mathrm{HgCdTe}$ material is roughly $780 \mathrm{~cm}^{-1}$ at the detector operation temperature of $50 \mathrm{~K}$, which is maintained by a Stirling cooler.

The interferometer itself is cooled with liquid carbon dioxide that is sprayed into the cooler tank under high pressure through small injection pipes. The carbon dioxide pressure drops sharply at the exit holes of the pipes, leading to adiabatic cooling and to the generation of carbon dioxide snow. The carbon dioxide snow keeps the instrument at its operating temperature range of 200 to $220 \mathrm{~K}$ for approximately $24 \mathrm{~h}$ (Piesch et al., 2014). The operating temperature has been chosen as an optimal compromise between technical complexity and improved noise performance. A lower operating temperature would have required evacuation of the instrument leading to increased mass and volume. Furthermore, it would not have led to a significant increase of signal-tonoise performance, since full integration time efficiency of the detection system can be reached at the chosen operating temperature.

\subsection{Calibration}

The radiometric calibration system consists of two identical large-area high-precision blackbody radiation sources, which are independently stabilised at two different temperatures with the help of thermoelectric coolers (Olschewski et al., 2013). The achievable temperatures of the blackbodies depend on the ambient temperature and pressure, with the colder of the two reaching at least $10 \mathrm{~K}$ below ambient. The blackbodies are cavities with aluminium pyramids on the baseplate. The emissivity of the blackbodies is required to be better than 0.997 and the temperature uncertainty to be better than $0.1 \mathrm{~K}$ in order to reach the radiometric calibration uncertainty target of $1 \%$ (Monte et al., 2014). In addition, the gimballed frame allows us to direct the centre of the FOV to $10^{\circ}$ upwards at the $90^{\circ}$ position of the yaw gimbal. Scene spectra taken at this position can be used as proxies for deepspace spectra. They serve as complementary calibration input for direct offset estimation after the removal of residual atmospheric emission lines.

Spectral calibration is achieved by the analysis of the spectral position of selected $\mathrm{CO}_{2}$ lines in the range of 940 to $972 \mathrm{~cm}^{-1}$. The scene spectra of the upward measurements are best suited for this purpose because they are usually free of clouds over the whole FOV.

\subsection{Gimballed frame and pointing}

As scientifically required, the gimbal mount provides agility on all three axes. For all gimbal angles set to $0^{\circ}$, the gimbal coordinate system is congruent with the aircraft system. When looking across track, the gimbal pitch frame compensates aircraft roll movements. The gimbal yaw level is free to move from -20 to $140^{\circ}$ relative to the aircraft longitudinal axis. Thus, it grants a view of the atmospheric limb in a range from 45 to $135^{\circ}$ and access to the two blackbodies that are mounted at gimbal yaw angles of about -10 and $20^{\circ}$. Depending on the carrier aircraft and mounting position of the instrument, angular views above $128^{\circ}$ may be obstructed by the aircraft wing and, accordingly, will not be used during measurements. The gimbal roll level allows compensating for aircraft movements that would otherwise rotate the FOV between 0 and $10^{\circ}$. The gimbal pitch level is agile from $14^{\circ}$ for deep-space calibration measurements down to $-98^{\circ}$ for nadir observation.

The pointing accuracy requirements can only be fulfilled with high-precision sensors. Measurements from an inertial measurement unit (IMU) with laser gyroscopes on the gimbal yaw frame and a three-axis microelectromechanical (MEMS) gyroscope on the pitch frame as well as information from a GPS and inductive angular encoders are fused to provide both fast attitude changes and stabilisation of the FOV. The navigation and gimbal control system was developed in collaboration with iMAR Navigation GmbH, Germany. All gimbal levels are powered by direct-drive motors 
and independent drive controller units. An additional camera operating in the visible spectral domain is mounted on the interferometer. This camera covers a wide FOV, thereby completely enclosing the FOV of the spectrometer. For most of the interferograms, correlated images of the scene or video sequences are taken. The information provided by this camera can be used for cloud identification and for pointing quality analysis.

\subsection{Data acquisition concept}

The general data acquisition concept is straightforward and simple but technically demanding. All scientific raw data are stored on a fast solid-state disk array in the aircraft. No attempt is made to process a significant part of the data during flight since adequate telemetry bandwidth to send the data to ground is not available on civil aircraft. The most important goals of the electronics design were to provide highbandwidth storage capabilities and to allow semi-automatic instrument control by supplying meaningful housekeeping and data quality parameters. A modular scalable design allowed for the parallel development of the different functional units and facilitates repair in the case of the malfunction of units.

The command and control communication infrastructure for the main functional units (interferometer electronics, pointing control, the different power control units, additional devices such as the visual cloud camera and the central control computer) is realised by Ethernet. Communication is based on a custom-made slim and flexible software architecture and protocol. On the ground, operators can connect to the instrument via a wireless interface. During flight, a lowbandwidth connection with an Iridium link provides limited access to command and control of the instrument. On HALO an optional in-flight operator computer can be directly connected to the instrument local area network (LAN). The operator can use the Iridium link for low-bandwidth text-based communication with the ground crew.

The IR data is digitised with 14 bit analogue-digital converters in the detector front-end electronics; each IR image is tagged with a time stamp issued from an $80 \mathrm{MHz}$ clock within the interferometer data acquisition electronics and then sent to storage via the Camera-Link interface. This additional high-speed link, dedicated to the transfer of the measured interferograms, guarantees continuous data throughput and avoids congestion of the command and control LAN. The reference laser zero crossings are detected with high temporal resolution, and the time stamps of these events, issued from the same clock as for the IR images, are sent to storage via LAN.

\subsection{Data processing}

IR interferograms are reconstructed post-flight for each pixel on a common, spatially equidistant sampling grid using
Brault's interpolation method (Brault, 1996). Spectral calibration parameters are derived from atmospheric signatures in a pre-processing step. Apparent image distance, the position of the optical axis on the array and a linear spectral scaling factor are determined. These parameters feed a simple model that is used in the reconstruction process of the interferograms (Kleinert et al., 2014). The first processing step also includes a non-linearity correction based on a common correction curve for all pixels derived from laboratory characterisation of the detector module (Sha, 2013). The interferograms are then Fourier-transformed into complex spectra.

Three different data sets are available for radiometric calibration: a deep-space view, with the instrument looking $10^{\circ}$ upwards, and two blackbody views with different temperatures. Since the instrument optics are thermally drifting, with a rate of approximately $1 \mathrm{~K} \mathrm{~h}^{-1}$, calibration measurements are performed every 30 to $45 \mathrm{~min}$. The deep-space measurements are contaminated by atmospheric lines that are removed by the subtraction of forward-calculated spectra using climatological parameterisation and a preliminary estimate of the spectrometer gain. In the next step, the spectrometer gain is determined from the cold blackbody measurement and the offset estimate. The spectra are calibrated in the complex domain following the approach introduced by Revercomb et al. (1988). The resulting hypercubes of calibrated data are an interim product with full spatial and spectral resolution. They can be used for image analysis, e.g. cloud determination.

After the application of a bad-pixel mask that eliminates pixels with radiometric gain errors larger than $1.5 \%$, the calibrated data are spatially co-added to row averages. The final data product is a column of 128 calibrated spectra per measurement and is fed into different retrieval codes (Ungermann et al., 2010; Woiwode et al., 2012; Kaufmann et al., 2014), depending on the scientific focus of the measurement. Figure 5 shows a sequence of CM spectra over the full spectral range measured by the instrument, and Fig. 6 is a zoom in the spectral range of 830 to $900 \mathrm{~cm}^{-1}$. The spectra are apodised with the Norton-Beer strong function (Norton and Beer, 1976).

\section{Instrument performance}

The first flights of GLORIA took place within the ESA Sounder Campaign (ESSenCe) on the M55 Geophysica from Kiruna in northern Sweden in December 2011. Two successful technological flights into the Arctic were performed. In late summer 2012, GLORIA was embedded in the Transport and Composition in the upper Troposphere and lowermost Stratosphere (TACTS) and Earth System Model Validation (ESMVal) campaigns. Scientific flights over Europe and the Atlantic were performed with the HALO aircraft from Oberpfaffenhofen in southern Germany. In addition, HALO circled Africa and performed an excursion 


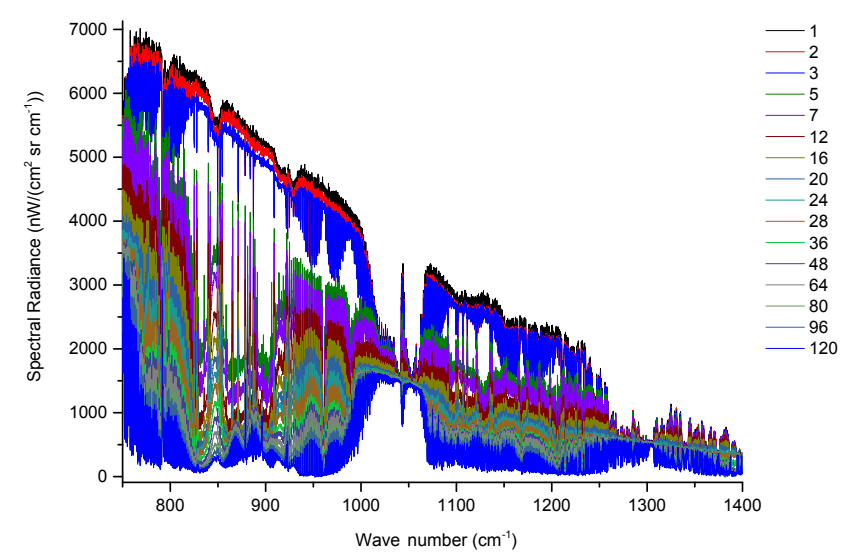

Figure 5. Calibrated spectra measured in chemistry mode during the flight on 26 September 2012 above the North Atlantic Ocean. The spectra cover the full spectral range of the instrument. The labels indicate the row number on the detector array. To improve readability, not all 128 rows are shown. Row 1 corresponds to the lowermost tangent altitude of approximately $5 \mathrm{~km}$, row 96 corresponds approximately to the flight altitude of $14 \mathrm{~km}$, and row 120 corresponds approximately to a viewing angle of $0.8^{\circ}$ above horizon. The spectra are generated by co-adding all spectra of one row; total integration time is $12 \mathrm{~s}$.

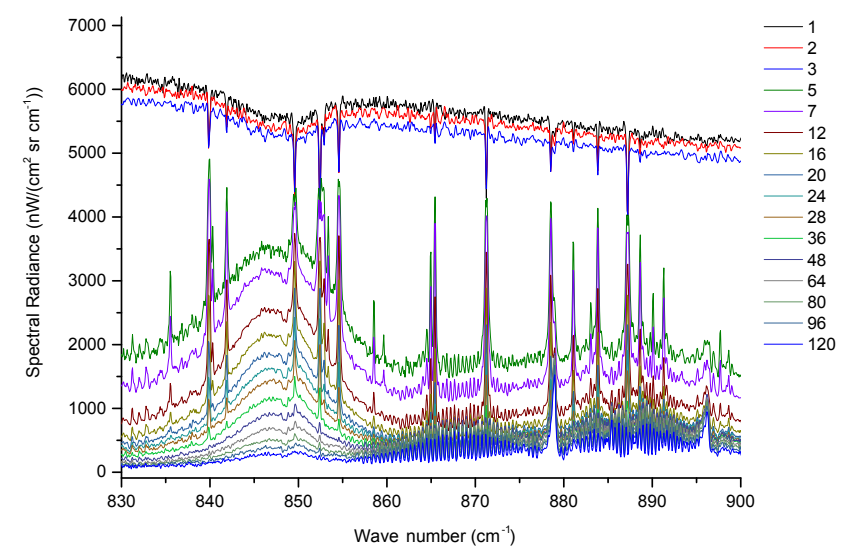

Figure 6. Calibrated spectra measured in chemistry mode during the flight on 26 September 2012 above the North Atlantic Ocean. A zoom of the data set of Fig. 5 in the spectral region of between 830 and $900 \mathrm{~cm}^{-1}$ is shown.

towards Antarctica. GLORIA encountered various climatological conditions ranging from mid-latitude summer to tropics and Antarctic winter. Thirteen scientific flights with more than 100 flight hours in total were carried out. GLORIA delivered data from all but one flight. It was operated in all scientific operation modes including tomography mode. The following section concentrates on the verification of the compliance with the overarching scientific requirements of flight data. Detailed characterisation and performance analysis on a subsystem level will be described in future publications.
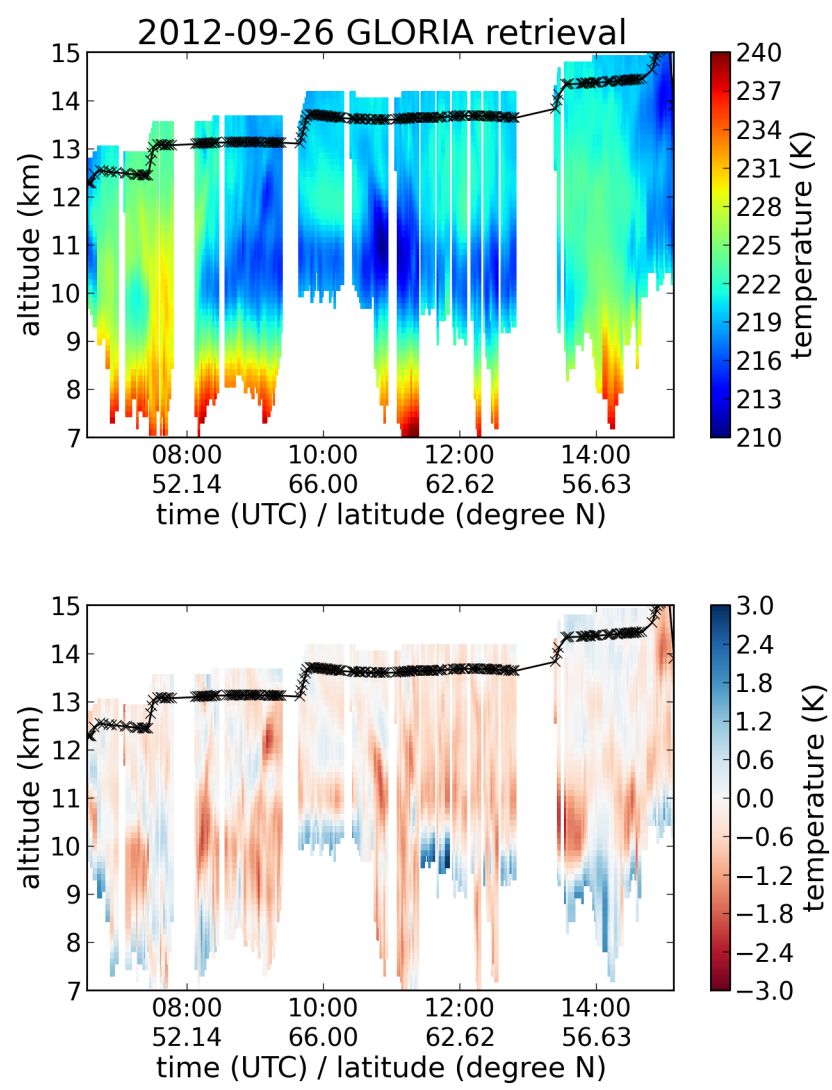

Figure 7. Upper panel: retrieval result for temperature for the flight on 26 September 2012 above the North Atlantic Ocean. The flight altitude of HALO is indicated by black crosses. The lower boundary of the retrieval is determined by clouds. Lower panel: temperature difference between the retrieval result and the ECMWF analysis.

Figure 7 depicts an overview of the result of the dynamics mode temperature retrieval for the flight over the North Atlantic on 26 September 2012. Good-quality temperature information is available from the ECMWF. We used the analysis model with a horizontal resolution of $16 \mathrm{~km}$ and interpolated the model data linearly in space and time to the location of the measurement points, i.e. to the tangent points. The comparison of the retrieved data with this interpolated ECMWF data provides an opportunity for an overall quality check on the product level.

Compliance with geometrical instrument requirements, i.e. the vertical extension and the correct placement of the FOV at the horizon can be verified with this data set. Figure 8 illustrates the agreement of the retrieval result with the ECMWF field. The retrieval has been performed without using the model data for the construction of the a priori information. The retrieval for a nominal FOV of $4.08^{\circ}$ as derived from engineering data and focal-length determination during spectral calibration is compared to a retrieval where the FOV was assumed to be $1 \%$ larger and smaller. The nominal FOV shows the smallest average difference between 


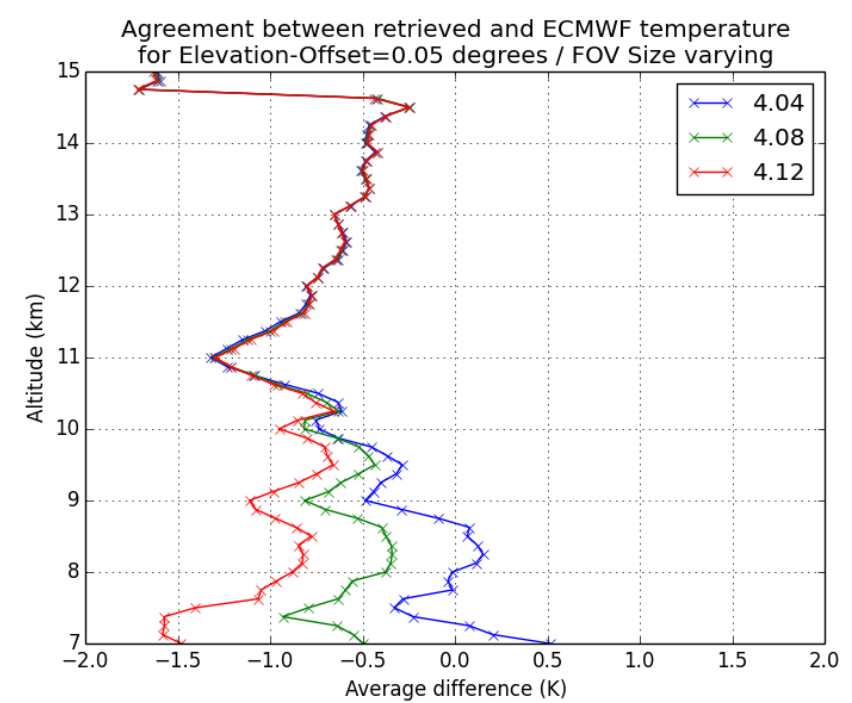

Figure 8. Deviations of temperature retrieval results for different FOV sizes. Average difference between ECMWF analysis and temperature retrieval is shown for the flight on 26 September 2012. The blue line indicates the average difference for an assumed vertical FOV of $4.04^{\circ}$, the red line for an assumed vertical FOV of $4.08^{\circ}$ and the green line for an assumed vertical FOV of $4.12^{\circ}$.

retrieved temperature and ECMWF field. A negative bias of approximately $0.5 \mathrm{~K}$ is seen over most of the altitude range. Due to the limb-observing geometry, the largest sensitivity to a FOV scaling error is seen in the lower altitudes. The results indicate that an erroneous reconstruction of the retrieval grid is detectable. This inherently verifies other geometrical requirements such as sampling size in vertical and horizontal direction. The mean pointing offset for this particular flight is determined to be approximately $0.05^{\circ}$ by minimising the variance of the deviation.

Vertical resolution of the instrument can be directly deduced from IR images showing cloud structures. Figure 9 shows an IR image of a subvisible cirrus cloud taken during a flight over the North Atlantic Ocean on 26 September 2012. It illustrates the in-flight imaging quality of the IR system. In parts, the observed cirrus layer is as thin as one pixel row. Vertical resolution of the retrieval can be derived from retrieval diagnostics. Figure 10 depicts the achieved vertical resolution for the trace gas $\mathrm{HNO}_{3}$ and demonstrates the agreement with the scientific requirement. The retrieval diagnostics in chemistry mode indicates a vertical resolution of the product of 280 to $400 \mathrm{~m}$. The difference in mixing ratio and vertical resolution are based on the retrieval characteristics of the codes used, in particular on the selection of the spectral windows and on the regularisation scheme.

Compliance with yaw agility and temporal sampling requirements for the tomography mode is illustrated in Fig. 11. The yaw and pitch movement of the gimbal during one tomography sequence is shown. The yaw angle is decremented from 128 to $44^{\circ}$ in $4^{\circ}$ steps. Every measurement

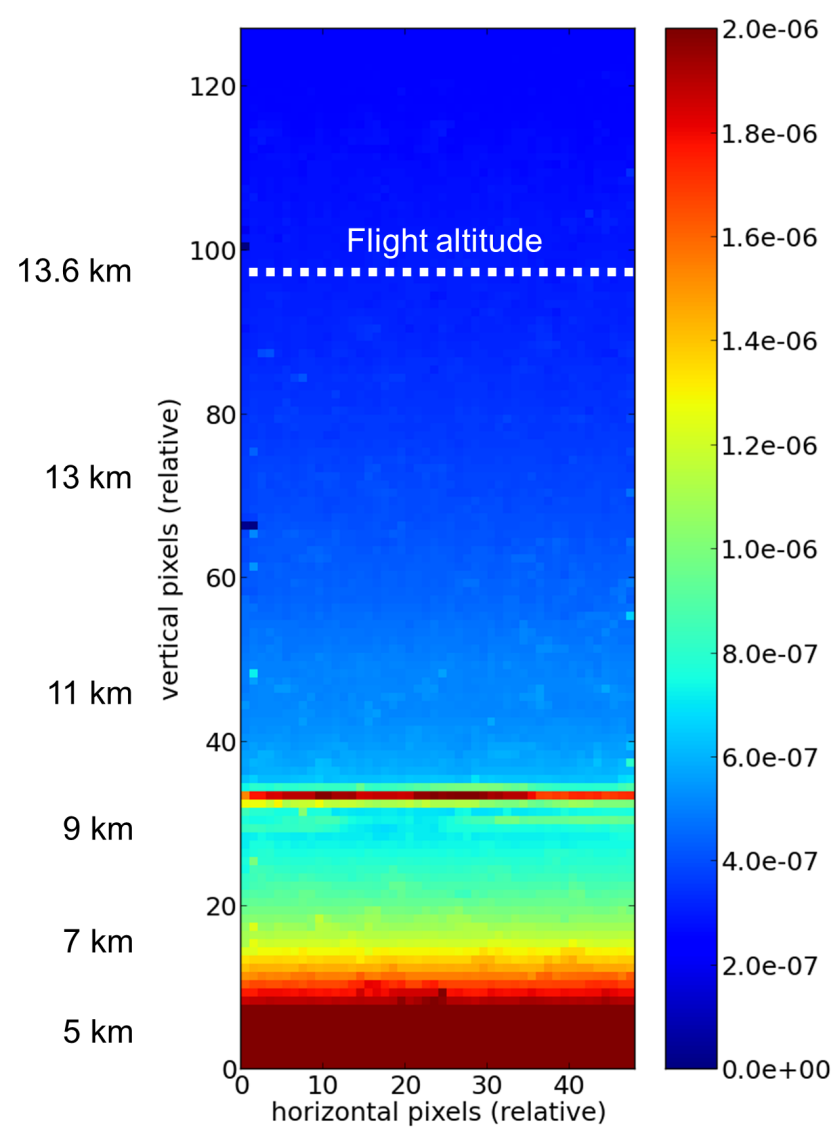

Figure 9. Radiance image taken on 26 September 2012 over the North Atlantic Ocean. The image shows mean radiance in watts $\left(\mathrm{cm}^{2} \mathrm{srcm}^{-1}\right)^{-1}$ between 800 and $950 \mathrm{~cm}^{-1}$. Approximate altitudes of tangent points are indicated by the scale on the left-hand side. A thin Cirrus cloud layer can be seen at an altitude of approximately $9.5 \mathrm{~km}$. The white dotted horizontal line indicates the flight altitude of $13.6 \mathrm{~km}$.

point represents one column of 128 spectra; 42 columns are recorded in $84 \mathrm{~s}$. The pitch angle variation over the measurement sequence is caused by the compensation of the pitch and roll movements of the aircraft. The result of a successful tomographic retrieval is shown by Riese et al. (2014).

Pointing stability is characterised using IR image analysis methods combined with the evaluation of attitude sensor data. The analysis of image motion in the IR data leads to pointing information with high temporal resolution due to the detector frame rate of $6.3 \mathrm{kHz}$. Various image analysis methods have been implemented and are currently being tested. Housekeeping data of the navigation and gimbal control unit and the three-axis MEMS gyro is used to complement this analysis. Preliminary results indicate compliance with requirements. The detailed analysis will be published elsewhere.

The spectral coverage and sensitivity of the instrument can be deduced from Fig. 12. The given values for the dynamics mode are derived from the variance of a sequence 

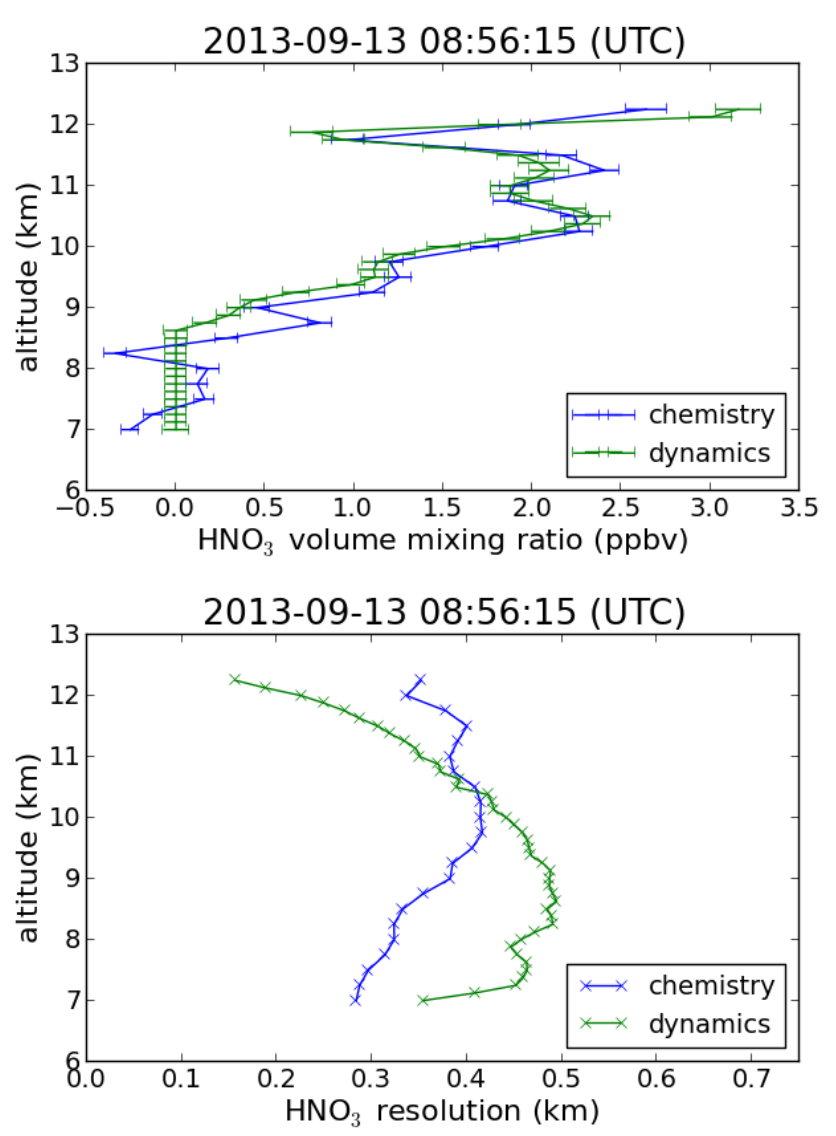

Figure 10. Typical retrieval result for $\mathrm{HNO}_{3}$ from 13 September 2012 between Cape Town and Antarctica. A data cube with chemistry mode spectral resolution has been processed with the chemistry mode retrieval code and, for comparison, also with dynamics mode spectral resolution and dynamics mode retrieval code.

of blackbody measurements during flight and can be seen as a conservative estimate of the performance during atmospheric measurements. The values indicate that GLORIA is closer to target than to threshold requirements over most of the spectral range. The spectral cut-off of the detector is rather soft and the region from 780 to $900 \mathrm{~cm}^{-1}$ is already in the cut-off slope, leading to a small non-compliance in the wave number region below $800 \mathrm{~cm}^{-1}$. Even better sensitivity was expected from the analysis of individual pixels, but spatial co-addition to row averages does not improve the noise values as fully as expected, suggesting a spatially correlated electronic noise source. The noise equivalent spectral radiance (NESR) analysis in CM mode in Fig. 12 is performed with a deep-space measurement. In this mode, the instrument complies with target requirements over most of the spectral range. Here, the noise determination is based on the statistics over the 128 rows.

The consistently good quality of temperature retrievals with an overall bias of approximately $0.5 \mathrm{~K}$ (see Fig. 8) is an indicator of a sufficient radiometric performance of the

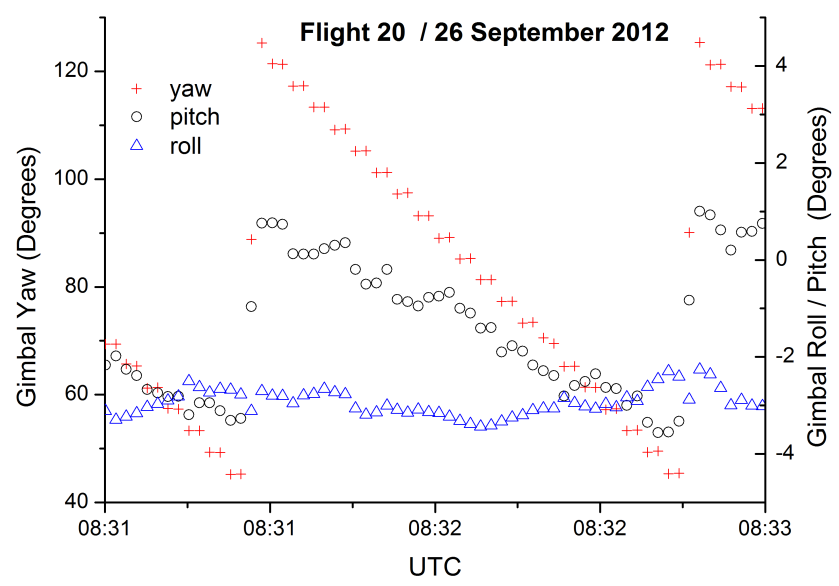

Figure 11. Yaw and pitch movement of the gimbal during one tomography sequence. Every measurement point represents one interferogram. Aircraft angle variations are the reason for the variability of the gimbal angles. Azimuth, elevation and image rotation of the FOV are the stabilised quantities.

instrument. A detailed analysis using redundant in-flight calibration measurements is ongoing. First results are presented in Kleinert et al. (2014) and indicate a radiometric accuracy of better than $1.5 \%$ over most of the spectral range.

The instrumental line shape (ILS) is determined through modelling of the instrument: the point spread function is calculated with the help of a ray-tracing program and then fed into a numerical ILS model. The applicability of these calculations to the real instrument has been verified by lab measurements with a gas cell. Figure 13 depicts the calculated ILS function for the chemistry mode for a corner pixel of the nominal field of view in comparison to the ideal ILS for a wavelength of $10 \mu \mathrm{m}$. The calculated ILS function has been re-centred to correct for the scaling of the wave number axis. The impact of the field position of the pixel on ILS maximum and asymmetry can be seen clearly in this worst-case scenario. The impact on line width is in the range of a few percent. The effects are more than an order of magnitude less pronounced in dynamics mode due to the significantly lower spectral resolution. The modelled ILS will be used in future in the retrieval process both in chemistry and dynamics mode. The current preliminary L2 data set has been produced without the use of the ILS model for practical implementation reasons. Spectral calibration is already performed in L0 processing; the accuracy is regularly checked in the retrieval process.

\section{Conclusions and outlook}

GLORIA has been deployed in three different scientific campaigns (ESSenCe, 2011; TACTS and ESMVal in 2012) on two different aircraft - Geophysica, HALO - in various climatic conditions. The instrument has demonstrated the 


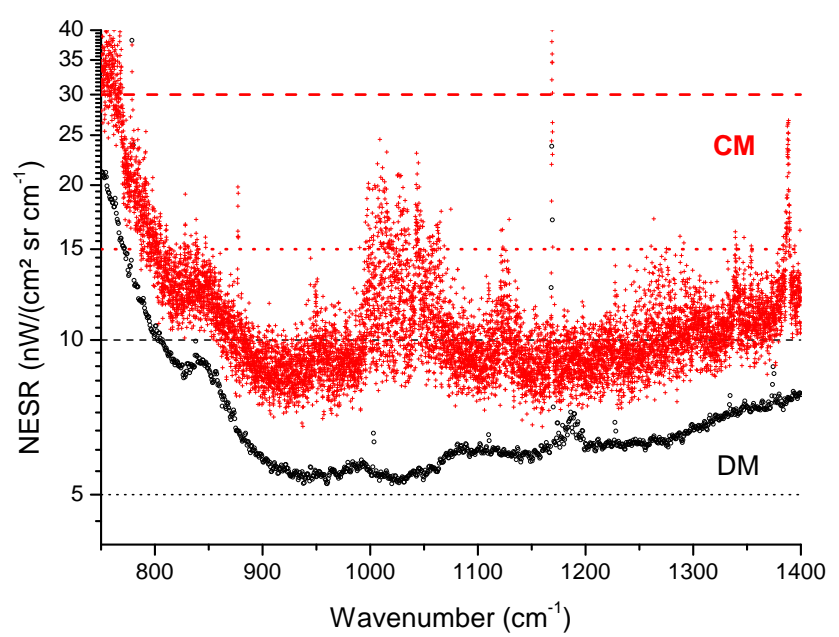

Figure 12. Sensitivity analysis for a calibration sequence of the flight on 26 September 2012. The dotted/dashed lines in black and red depict the target/threshold requirements for DM and CM, respectively. The black circles represent the mean noise equivalent spectral radiance (NESR) values for the L1 product based on statistics of 43 consecutive real blackbody spectra. Spectral sampling is $0.625 \mathrm{~cm}^{-1}$; total integration time is $1.2 \mathrm{~s}$. The red crosses show the mean NESR for one deep-space measurement based on the statistics over the 128 rows. Spectral sampling is $0.0625 \mathrm{~cm}^{-1}$; total integration time is $12 \mathrm{~s}$.

capability of the infrared limb-imaging technique to provide atmospheric parameters like temperature and trace gas fields with very high spatial resolution. This allows to address some of the most pressing scientific questions regarding physical and chemical processes in the UTLS as outlined in the accompanying paper of Riese et al. (2014).

The initial instrument concept has proven to be adequate and the experience of the first year of operation does not force us to make substantial changes to the overall set-up or to essential subsystems. Some areas for further improvement have been identified, though. In particular spatially correlated noise sources in the detection chain, such as electromagnetic compatibility problems and electronic noise, will be addressed to improve sensitivity and radiometric accuracy over the full spectral range. Non-linearity characteristics of the $\mathrm{HgCdTe}$ detector arrays will be characterised in depth to allow optimal operation and ease processing. Upgrades to some electronics units will improve performance, reliability and operability of the instrument. In order to reduce acoustic and vibration excitation of the instrument, the opening in the belly pod of the HALO aircraft will be modified to improve aerodynamics.

Acknowledgements. We acknowledge financial support by the Helmholtz society (ATMO, ATMONSYS) and by the Deutsche Forschungsgemeinschaft.

The ESSenCe campaign was supported by the Earth Observation Envelope Programme of the European Space Agency (ESA). We
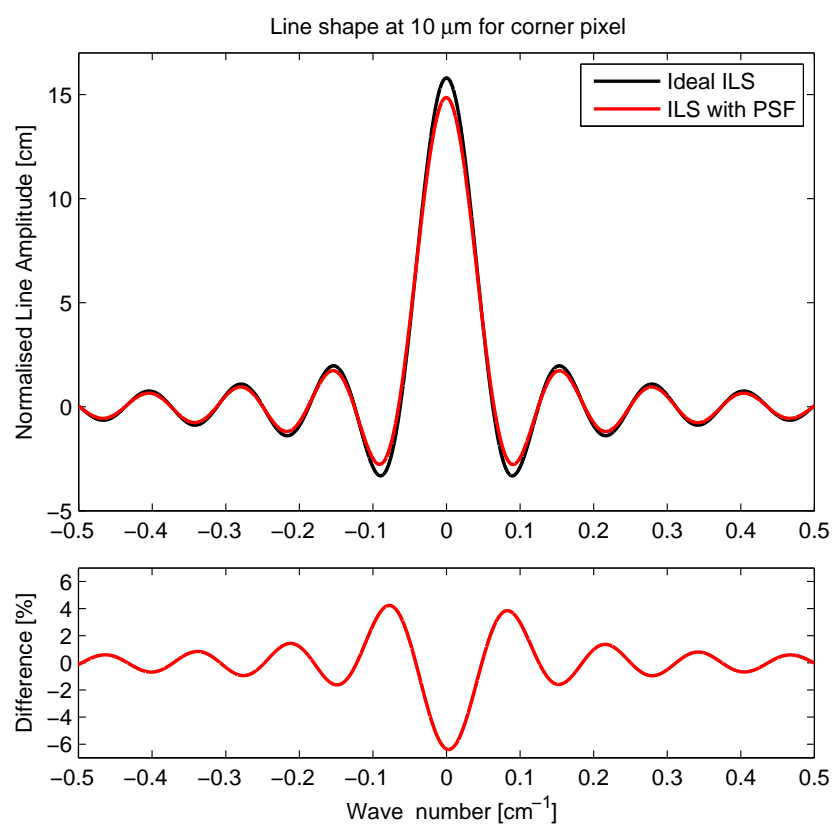

Figure 13. Modelled ILS function for an optical path difference of $8 \mathrm{~cm}$ (chemistry mode) for the corner pixel of the nominal field of view in comparison to the ideal ILS for a wavelength of $10 \mu \mathrm{m}$.

thank D. Schuettemeyer at ESTEC for his support and the M55Geophysica Team and the Kiruna airport crew for their outstanding commitment during this campaign.

We thank the TACTS and ESMVal coordinators for organising these extraordinarily successful scientific campaigns and the whole team of DLR flight operations at Oberpfaffenhofen for excellent HALO flights, patience and trusting support. Last but not least, we want to thank the certification team of DLR for helping us navigate the cliffs of the certification process safely.

We acknowledge support by the Deutsche Forschungsgemeinschaft and the Open Access Publishing Fund of the Karlsruhe Institute of Technology.

The service charges for this open access publication have been covered by a Research Centre of the Helmholtz Association.

Edited by: J. Notholt

\section{References}

Aumann, H., Chahine, M., Gautier, C., Goldberg, M., Kalnay, E., McMillin, L., Revercomb, H., Rosenkranz, P., Smith, W., Staelin, D., Strow, L., and Susskind, J.: AIRS/AMSU/HSB on the aqua mission: design, science objectives, data products, and processing systems, IEEE T. Geosci. Remote, 41, 253-264, doi:10.1109/TGRS.2002.808356, 2003.

Bacmeister, J. T., Küll, V., Offermann, D., Riese, M., and Elkins, J. W.: Intercomparison of satellite and aircraft observations of ozone, CFC-11, and $\mathrm{NO}_{\mathrm{y}}$ using trajectory mapping, J. Geophys. Res.-Atmos., 104, 16379-16390, 1999. 
Barré, J., Peuch, V.-H., Attié, J.-L., El Amraoui, L., Lahoz, W. A., Josse, B., Claeyman, M., and Nédélec, P.: Stratospheretroposphere ozone exchange from high resolution MLS ozone analyses, Atmos. Chem. Phys., 12, 6129-6144, doi:10.5194/acp12-6129-2012, 2012.

Beer, R., Glavich, T. A., and Rider, D. M.: Tropospheric emission spectrometer for the Earth Observing System's Aura satellite, Appl. Optics, 40, 2356-2367, doi:10.1364/AO.40.002356, 2001.

Brault, J. W.: New approach to high-precision Fourier transform spectrometer design, Appl. Optics, 35, 2891-2896, doi:10.1364/AO.35.002891, 1996.

Elwell, J. D., Cantwell, G. W., Scott, D. K., Esplin, R. W., Hansen, G. B., Jensen, S. M., Jensen, M. D., Brown, S. B., Zollinger, L. J., Thurgood, V. A., Esplin, M. P., Huppi, R. J., Bingham, G. E., Revercomb, H. E., Best, F. A., Tobin, D. C., Taylor, J. K., Knuteson, R. O., Smith, W. L., Reisse, R. A., and Hooker, R.: A geosynchronous imaging Fourier transform spectrometer (GIFTS) for hyperspectral atmospheric remote sensing: instrument overview and preliminary performance results, Proc. SPIE, 6297, 62970S, doi:10.1117/12.684135, 2006.

ESA: Report for Mission Selection: PREMIER, Vol. SP-1324/3, ESA Communication Production Office, Noordwijk, the Netherlands, 2012.

Fischer, H., Birk, M., Blom, C., Carli, B., Carlotti, M., von Clarmann, T., Delbouille, L., Dudhia, A., Ehhalt, D., Endemann, M., Flaud, J. M., Gessner, R., Kleinert, A., Koopman, R., Langen, J., López-Puertas, M., Mosner, P., Nett, H., Oelhaf, H., Perron, G., Remedios, J., Ridolfi, M., Stiller, G., and Zander, R.: MIPAS: an instrument for atmospheric and climate research, Atmos. Chem. Phys., 8, 2151-2188, doi:10.5194/acp-8-2151-2008, 2008.

Friedl-Vallon, F., Maucher, G., Kleinert, A., Lengel, A., Keim, C., Oelhaf, H., Fischer, H., Seefeldner, M., and Trieschmann, O.: Design and characterisation of the balloon-borne Michelson Interferometer for Passive Atmospheric Sounding (MIPAS-B2), Appl. Optics, 43, 3335-3355, 2004.

Gille, J. C. and Barnett, J. J.: Conceptual design of the High-Resolution Dynamics Limb Sounder (HIRDLS) for the EOS chemistry mission, Proc. SPIE, 2830, 190-201, doi:10.1117/12.256115, 1996.

Gille, J. C. and Russell, J. M.: The limb infrared monitor of the stratosphere: experiment description, performance, and results, J. Geophys. Res., 89, 5125-5140, 1984.

Kaufmann, M., Blank, J., Guggenmoser, T., Ungermann, J., Engel, A., Ern, M., Friedl-Vallon, F., Gerber, D., Grooss, J. U., Guenther, G., Höpfner, M., Kleinert, A., Latzko, Th., Maucher, G., Neubert, T., Nordmeyer, H., Oelhaf, H., Olschewski, F., Orphal, J., Preusse, P., Schlager, H., Schneider, H., Schuettemeyer, D., Stroh, F., Suminska-Ebersoldt, O., Vogel, B., Volk, C. M., Woiwode, W., and Riese, M.: Retrieval of three-dimensional small scale structures in upper tropospheric/lower stratospheric composition as measured by GLORIA, Atmos. Meas. Tech. Discuss., 7, 4229-4274, doi:10.5194/amtd-7-4229-2014, 2014.

Kleinert, A., Friedl-Vallon, F., Guggenmoser, T., Höpfner, M., Neubert, T., Ribalda, R., Sha, M. K., Ungermann, J., Blank, J., Ebersoldt, A., Kretschmer, E., Latzko, T., Oelhaf, H., Olschewski, F., and Preusse, P.: Level 0 to 1 processing of the imaging Fourier transform spectrometer GLORIA: generation of radiometrically and spectrally calibrated spectra, Atmos. Meas. Tech. Discuss., 7, 2827-2878, doi:10.5194/amtd-7-2827-2014, 2014.
Kunde, V. G., Brasunas, J. C., Conrath, B. J., Hanel, R. A., Herman, J. R., Jennings, D. E., and Maguire, W. C.: Infrared spectroscopy of the lower stratosphere with a balloon-borne cryogenic Fourier spectrometer, Appl. Optics, 26, 545-553, 1987.

Monte, C., Gutschwager, B., Adibekyan, A., Kehrt, M., Ebersoldt, A., Olschewski, F., and Hollandt, J.: Radiometric calibration of the in-flight blackbody calibration system of the GLORIA interferometer, Atmos. Meas. Tech., 7, 13-27, doi:10.5194/amt-7-132014, 2014.

Norton, R. H. and Beer, R.: New apodization functions for Fourier spectroscopy, J. Opt. Soc. Am., 66, 259-264, 1976.

Oelhaf, H., Clarmann, T., Fischer, H., Friedl-Vallon, F., Fritzsche, C., Linden, A., Piesch, C., Seefeldner, M., and Völker, W.: Stratospheric $\mathrm{ClONO}_{2}$ and $\mathrm{HNO}_{3}$ profiles inside the Arctic vortex from MIPAS-B limb emission spectra obtained during EASOE, Geophys. Res. Lett., 21, 1263-1266, doi:10.1029/93GL01303, 1994.

Offermann, D., Grossmann, K.-U., Barthol, P., Knieling, P., Riese, M., and Trant, R.: Cryogenic Infrared Spectrometers and Telescopes for the Atmosphere (CRISTA) experiment and middle atmosphere variability, J. Geophys. Res.-Atmos., 104, 16311-16325, doi:10.1029/1998JD100047, 1999.

Olschewski, F., Ebersoldt, A., Friedl-Vallon, F., Gutschwager, B., Hollandt, J., Kleinert, A., Monte, C., Piesch, C., Preusse, P., Rolf, C., Steffens, P., and Koppmann, R.: The in-flight blackbody calibration system for the GLORIA interferometer on board an airborne research platform, Atmos. Meas. Tech., 6, 3067-3082, doi:10.5194/amt-6-3067-2013, 2013.

Pan, L. L., Randel, W. J., Gille, J. C., Hall, W. D., Nardi, B., Massie, S., Yudin, V., Khosravi, R., Konopka, P., and Tarasick, D.: Tropospheric intrusions associated with the secondary tropopause, J. Geophys. Res.-Atmos., 114, D10302, doi:10.1029/2008JD011374, 2009.

Piesch, C., Sartorius, C., Friedl-Vallon, F., Gulde, T., Heger, S., Kretschmer, E., Maucher, G., Nordmeyer, H., Barthel, J., Ebersoldt, A., Graf, F., Hase, F., Kleinert, A., Neubert, T., and Schillings, J.: The mechanical and thermal setup of the GLORIA spectrometer, Atmos. Meas. Tech. Discuss., in preparation, 2014.

Revercomb, H. E., Buijs, H., Howell, H. B., LaPorte, D. D., Smith, W. L., and Sromovsky, L. A.: Radiometric calibration of IR Fourier transform spectrometers: solution to a problem with the High-Resolution Interferometer Sounder, Appl. Optics, 27, 3210-3218, doi:10.1364/AO.27.003210, 1988.

Riese, M., Preusse, P., Spang, R., Ern, M., Jarisch, M., Grossmann, U., and Offermann, D.: Measurements of trace gases by the cryogenic infrared spectrometers and telescopes for the atmosphere CRISTA experiment, Adv. Space Res., 19, 563-566, doi:10.1016/S0273-1177(97)00172-5, 1997.

Riese, M., Spang, R., Preusse, P., Ern, M., Jarisch, M., Offermann, D., and Grossmann, K. U.: Cryogenic Infrared Spectrometers and Telescopes for the Atmosphere (CRISTA) data processing and atmospheric temperature and trace gas retrieval, J. Geophys. Res.-Atmos., 104, 16349-16367, doi:10.1016/S02731177(97)00172-5, 1999.

Riese, M., Ploeger, F., Rap, A., Vogel, B., Konopka, P., Dameris, M. L., and Forster, P.: Impact of uncertainties in atmospheric mixing on simulated UTLS composition and re- 
lated radiative effects, J. Geophys. Res.-Atmos., 117, D16305, doi:10.1029/2012JD017751, 2012.

Riese, M., Oelhaf, H., Preusse, P., Blank, J., Ern, M., FriedlVallon, F., Fischer, H., Guggenmoser, T., Höpfner, M., Hoor, P., Kaufmann, M., Orphal, J., Plöger, F., Spang, R., SuminskaEbersoldt, O., Ungermann, J., Vogel, B., and Woiwode, W.: Gimballed Limb Observer for Radiance Imaging of the Atmosphere (GLORIA) scientific objectives, Atmos. Meas. Tech., 7, 19151928, doi:10.5194/amt-7-1915-2014, 2014.

Rodriguez, A., Stuhlmann, R., Tjemkes, S., Aminou, D. M., Stark, H., and Blythe, P.: Meteosat Third Generation: mission and system concepts, Proc. SPIE, 7453, 74530C, doi:10.1117/12.824236, 2009.

Sabbah, S., Harig, R., Rusch, P., Eichmann, J., Keens, A., and Gerhard, J.-H.: Remote sensing of gases by hyperspectral imaging: system performance and measurements, Opt. Eng., 51, 111717, doi:10.1117/1.OE.51.11.111717, 2012.

Sha, M. K.: Characterization and Optimization of the new Imaging Fourier Transform Spectrometer GLORIA, Ph.D. thesis, Karlsruhe Institute of Technology (KIT), 2013.

Solomon, S., Rosenlof, K. H., Portmann, R. W., Daniel, J. S., Davis, S. M., Sanford, T. J., and Plattner, G.-K.: Contributions of stratospheric water vapor to decadal changes in the rate of global warming, Science, 327, 1219-1223, doi: 10.1126/science. $1182488,2010$.

Ungermann, J.: Tomographic reconstruction of atmospheric volumes from infrared limb-imager measurements, Ph.D. thesis, Forschungszentrum Jülich, Wuppertal University, Jülich, available at: http://hdl.handle.net/2128/4385 (last access: 4 March 2014), 2011.

Ungermann, J., Kaufmann, M., Hoffmann, L., Preusse, P., Oelhaf, H., Friedl-Vallon, F., and Riese, M.: Towards a 3-D tomographic retrieval for the air-borne limb-imager GLORIA, Atmos. Meas. Tech., 3, 1647-1665, doi:10.5194/amt-3-1647-2010, 2010.

Ungermann, J., Blank, J., Lotz, J., Leppkes, K., Hoffmann, L., Guggenmoser, T., Kaufmann, M., Preusse, P., Naumann, U., and Riese, M.: A 3-D tomographic retrieval approach with advection compensation for the air-borne limb-imager GLORIA, Atmos. Meas. Tech., 4, 2509-2529, doi:10.5194/amt-4-2509-2011, 2011.
Ungermann, J., Pan, L. L., Kalicinsky, C., Olschewski, F., Knieling, P., Blank, J., Weigel, K., Guggenmoser, T., Stroh, F., Hoffmann, L., and Riese, M.: Filamentary structure in chemical tracer distributions near the subtropical jet following a wave breaking event, Atmos. Chem. Phys., 13, 10517-10534, doi:10.5194/acp13-10517-2013, 2013.

Vallieres, A., Chamberland, M., Farley, V., Belhumeur, L., Villemaire, A., Giroux, J., and Legault, J.-F.: High-performance field-portable imaging radiometric spectrometer technology for chemical agent detection, Proc. SPIE, 5990, 59900U, doi:10.1117/12.632069, 2005.

von Clarmann, T., Höpfner, M., Kellmann, S., Linden, A., Chauhan, S., Funke, B., Grabowski, U., Glatthor, N., Kiefer, M., Schieferdecker, T., Stiller, G. P., and Versick, S.: Retrieval of temperature, $\mathrm{H}_{2} \mathrm{O}, \mathrm{O}_{3}, \mathrm{HNO}_{3}, \mathrm{CH}_{4}, \mathrm{~N}_{2} \mathrm{O}, \mathrm{ClONO}_{2}$ and $\mathrm{ClO}$ from MIPAS reduced resolution nominal mode limb emission measurements, Atmos. Meas. Tech., 2, 159-175, doi:10.5194/amt-2-159-2009, 2009.

Weigel, K., Hoffmann, L., Günther, G., Khosrawi, F., Olschewski, F., Preusse, P., Spang, R., Stroh, F., and Riese, M.: A stratospheric intrusion at the subtropical jet over the Mediterranean Sea: air-borne remote sensing observations and model results, Atmos. Chem. Phys., 12, 8423-8438, doi:10.5194/acp-12-84232012, 2012.

Woiwode, W., Oelhaf, H., Gulde, T., Piesch, C., Maucher, G., Ebersoldt, A., Keim, C., Höpfner, M., Khaykin, S., Ravegnani, F., Ulanovsky, A. E., Volk, C. M., Hösen, E., Dörnbrack, A., Ungermann, J., Kalicinsky, C., and Orphal, J.: MIPAS-STR measurements in the Arctic UTLS in winter/spring 2010: instrument characterization, retrieval and validation, Atmos. Meas. Tech., 5, 1205-1228, doi:10.5194/amt-5-1205-2012, 2012. 